\title{
RELAÇÕES INCESTUOSAS: ESCREVER A VIDA DE UM ESCRITOR O MEU CASO COM ALEXANDRE O'NEILL
}

\author{
Maria Antónia Oliveira ${ }^{1}$
}

RESUMO: A partir da experiência como biógrafa do poeta português Alexandre O'Neill, a autora deste trabalho desenvolve uma reflexão sobre os significados e usos da designação biografia literária' e sobre a especificidade de escrever a vida de outrem, sendo ele próprio um escritor, por comparação a outros tipos de biografia.

PALAVRAS-CHAVE: Biografia literária, relação vida / literatura, Alexandre O’Neill

RESUMÉ: A partir de son expérience en tant que biographe du poète portugais Alexandre O’Neill, l'auteur de ce travail mène une réflexion sur les significations et usages de l'expression 'biographie littéraire' et sur la spécificité qui constitue la narration écrite de la vie d'un autre qui est écrivain, en faisant la comparaison avec d'autres types de biographies.

MOTS-CLÉS : biographie littéraire, relation vie / littérature, Alexandre O’Neill

A poesia é a vida? Pois claro! Conforme a vida que se tem o verso vem - e se a vida é vidinha, já não há poesia que resista. O mais é literatura,

libertinura, pegas no paleio; o mais é isto: o tolo dum poeta a beber, dia a dia, a bica preta, convencido de si, do seu recheio...

A poesia é a vida? Pois claro! Embora custe caro, muito caro, e a morte se meta de permeio.

Alexandre O’Neill, “Autocrítica (achegas)”

Não foi sem grandes hesitações que escolhi o título para a biografia de Alexandre O’Neill, publicada em 2007 pela editora Dom Quixote. Bastante influenciada pela tradição inglesa, devo confessá-lo, acabei por escolher aquele que julguei mais explícito e inequívoco, Alexandre O’Neill. Uma biografia literária. O nome do meu biografado era sobejamente conhecido em Portugal. Além de poeta e escritor - como ele próprio lamentou numa crónica, "parece que o poeta não é bem escritor, substantivo reservado habitualmente para nomear o ficcionista” (O’NEILL, 2004, p. 172) -, também fora

\footnotetext{
${ }^{1}$ Investigadora doutoranda no iEMo (Instituto de Estudos sobre o Modernismo) e no Instituto de Estudos de Literatura Tradicional / IELT, da Universidade Nova de Lisboa.

Está neste momento a trabalhar na biografia de Almada Negreiros, em colaboração com a equipa do projecto Modernismo Online - Arquivo Virtual da Geração de Orpheu.
} 
publicitário, dramaturgo, locutor, conselheiro literário e jornalista, além de outras ocupações quase sempre relacionadas com a escrita que foi exercendo vida adentro.

Quanto ao resto do título, estava bem consciente do peso que ele imprimia ao livro, e da declaração de intenções que a minha escolha representava num país onde o género biográfico era escassamente cultivado, nomeadamente no que respeitava a narração da vida de escritores, escassamente representados enquanto tal.

A designação 'biografia literária' revelou-se controversa e deu azo a alguma suspeição e a interpretações díspares. Pretendo portanto esclarecer o que entendo por 'biografia literária', tentando afastar alguma névoa do título da minha narrativa e contribuir para a reflexão a partir de um termo naturalmente ferido de alguma ambiguidade.

$\mathrm{Na}$ tradição anglo-saxónica, utilizou-se durante muito tempo a designação 'biografia literária' para as histórias de vida de escritores e poetas - ou seja, para referir o objeto de um tipo de biografia específica e distinta, um subgénero enfim, sobre o qual existe vasta bibliografia teórica. Esta designação tornou-se porém sintoma da complexidade que envolve a tarefa específica de escrever a vida de outrem que se fez célebre, ou público, por escrever. É verdade que a relação entre vida e obra numa biografia literária é problema não resolvido - talvez porque cada escritor representa um caso, e a singularidade é alheia a regras. De qualquer modo, para qualquer estudante saído de uma faculdade de Letras do século XX um género que tendia a relacionar a vida e a obra escrita era um abismo bastante atraente.

Continue a fazer-se um pouco de história, agora menos pessoal. Havia, por um lado, nos estudos literários, o espectro do biografismo crítico, fenómeno que Antoine Compagnon designou em 1983 como a "vieuvre", ou seja, a utilização da vida do escritor para explicar ou criticar a sua obra. No que toca ao género biográfico, esta confusão resultava em narrativas de vida muito determinadas pela obra, quando não mesmo meras reproduções da obra entrecortadas com episódios de vida, ou com elas confundidas, de que são exemplo várias biografias de Camilo Castelo Branco, como a mais célebre de Alberto Pimentel, O romance do romancista, de 1890, ou a de Joaquim Ferreira, de 1956, uma extensa

\footnotetext{
${ }^{2}$ Citado por François Dosse (DOSSE, 2005, p. 85-86). Este termo veio a ser adoptado por vários críticos e teóricos franceses.
} 
compilação cronológica de citações de todo o tipo de textos camilianos, que leva inclusivamente o título anómalo Memórias de Camilo - extraídas das suas obras por Joaquim Ferreira. Existia de facto, tradicionalmente, uma tensão entre a vida e a obra, vacilante ou assumidamente tomada como autobiográfica. Ou então, do outro lado do espectro, já no século XX, a completa rejeição da figura do autor enquanto emissor, produtor, mesmo inventor do texto, até ao seu completo apagamento e morte.

$\mathrm{Na}$ verdade, tratou-se de um equívoco que confundia o género biografia e o biografismo crítico que almejava, fundamentalmente, chegar à intenção do autor ou localizar na vida a origem do texto. E aí surge Zuckerman, na pena de Rubem Fonseca. A entrada do Diário de um fescenino de 7 de agosto é inteiramente dedicada à relação entre literatura e vida, através de uma personagem de Philip Roth, Zuckerman, que encarna o inferno em que se torna a habitual e generalizada indistinção entre o que se convencionou chamar autor empírico e autor textual. A “síndrome de Zuckerman” é um abuso de que os escritores se queixam e sofrem agudamente, fruto de uma ingenuidade e singeleza que tanto pode ser do leitor como do biógrafo, e que ele, Rubem Fonseca, assume olimpicamente, ao enveredar, displicente, pela escrita (ficção?) diarística.

Ainda que não tivesse sido alcunhada, os autores sempre conheceram os efeitos da síndrome de Zuckerman. Quanto a mim, escrevo procurando estabelecer um imediatismo entre mim e o leitor. Desconsiderando possíveis equívocos exegéticos. O nome do meu personagem é: Eu. Outro dia, encontrei num bar um colega de profissão, sob o efeito de vapores etilicos, que me disse que eu era muito imprudente." (FONSECA, 2003, P. 123)

Esta imprudência é já uma forma muito pós-moderna de operar com a autobiografia. Como disse Pedro Almodovar, citando alguém antes dele, "se não é autobiográfico, é plágio." A obra do escritor e a sua abordagem crítica foram, portanto, motivos de embaraço para a biografia literária, que criou aliás um tipo específico que exprimia e desenvolvia esta ligação, a 'biografia crítica'. Posteriormente, abandonado este último formato, foram sendo preferidos títulos como o simples "Vida de...", ou "Uma vida de escritor", ou o já referido "Biografia literária", estes últimos acompanhados do nome do biografado.

Ultimamente, porém, veio a ganhar amplitude outra interpretação deste último termo, que deslocou o adjetivo do objecto de pesquisa para a forma do texto biográfico: seriam literárias as biografias que tivessem qualidade literária, e não necessariamente aquelas cujo objecto fosse a vida de um escritor. Note-se que esta posição reivindicativa diz bem da 
necessidade de reconhecimento e legitimação que o género biográfico continua a ter junto das comunidades literária e académica, por ambas continuada e longamente olhado de soslaio. A biografia é um género híbrido. Na pessoa do biógrafo misturam-se o historiador, o jornalista entrevistador e o detective; porventura ainda o psicólogo, o sociólogo e o antropólogo; eventualmente, o crítico literário. E, por fim, o escritor, o que escreve a narrativa de vida - um segundo autor, por direito e de facto. Este elevado grau de mestiçagem deixou a biografia numa espécie de no man's land, e tornou-a resistente à legitimação académica e à canonização literária: não era ficção, nem história, nem ensaio literário - e foi, por vezes, tudo isto simultaneamente.

Tal reinterpretação do conceito de "biografia literária" levanta evidentemente um problema de valoração e leva a discussão sobre o género para o terreno derrapante e infrutífero das questões essencialistas: o que é a arte, o que é a literatura. Regressa-se assim a uma controvérsia antiga, já teorizada por vários biógrafos: a de se saber se a biografia é uma arte, uma técnica, ou mesmo uma ciência. Virginia Woolf, nos seus dois ensaios sobre biografia, vai sempre hesitando entre chamar-lhe arte ou técnica - distinguindo-a, de todo o modo, da arte da ficção pela alta taxa de mortalidade, ou seja, pela sua perecidade (no que me parece ser uma definição de arte bastante conservadora, ainda que à luz da época). Mas onde os ensaios ao longo de quase todo o século XX - de Woolf, de Harold Nicholson ou de Leon Edel - eram subtis e analíticos, e contemplavam todas as fases do processo biográfico (a pesquisa, o tratamento de dados, a seleção de informação), chegamos agora à mesma polémica na sua forma mais simplista: está ou não bem escrito? E logo outra pergunta irrompe: o que é escrever bem? Ou ainda: quem determina se está bem escrito? O próprio biógrafo, que chama à sua biografia 'literária'? O editor? O leitor?

Não foi portanto à luz desta reinterpretação do adjetivo "literária" que dei o título à biografia de Alexandre O’Neill. Considerei muito mais produtiva e adequada a significação tradicional de "biografia literária": narrar a vida de um escritor. A partir de Donald J. Winslow, Catherine N. Parke tem esta mesma concepção, ao definir biografia literária como "a descriptive term for the lives of literary men and women", noting that there is "sometimes confusion in this phrase when it is used to describe the style of a biographical work rather than the subject matter.” (PARK, 2002, p.136). 
Eu podia, é certo, ter omitido a palavra literária. Mas era para mim quase necessário e mesmo inevitável ser explícita, ainda que sob pena de cair na redundância ou na incompreensão. Estava a escrever a vida do ponto de vista de um homem que por vocação, circunstâncias ou acaso, tinha sido escritor. A questão do literário era central na minha narrativa, mas não por uma qualquer intenção de estar ou não a fazer arte. Pois, na verdade, e como é natural, não pretendi fazer literatura, nem deixei de pretender.

O que quanto a mim singulariza a biografia literária é o seu carácter algo incestuoso, como certeiramente notou o biógrafo de Thomas Mann, Nigel Hamilton (HAMILTON, 1985, p.115-116). Escrever a vida de um homem de palavras difere de escrever a vida de um homem de ação - de um político, ou de um guerreiro. Não é também semelhante o processo de contar a vida de uma pop star, ou de um pintor artistas também, ainda assim, mas não da palavra. Trata-se aqui de alguém a escrever a vida de outro que escreve, ou escreveu. Esta espécie de endogamia é determinante na operação biográfica, e na enorme quantidade de opções que qualquer biografia implica, aumentada exponencialmente no caso de vida de escritores, que passo brevemente a referir. Ao escrever a biografia de Alexandre O’Neill, a minha perspectiva e decisões, desde a pesquisa à escrita, foram sendo sempre orientadas pelo pressuposto de que o meu biografado era escritor, e de que a sua vida foi sendo determinada por esta condição.

Neste sentido, e na fase da pesquisa, interessaram-me temas biográfico/literários como as circunstâncias da produção poética e de escrita, o reconhecimento público e a relação dele próprio com o estatuto de poeta; ou ainda a recepção dos livros pelo público e crítica e a reação de O’Neill à crítica e às influências poéticas que lhe eram apontadas.

Fosse a escrita de poemas (datados), a publicação de livros ou a colaboração na imprensa periódica, as suas incursões na escrita em domínios como a tradução, o cinema, o teatro ou a televisão - toda a obra de Alexandre O'Neill foi dando entrada na minha narrativa como um facto biográfico. Nestas ocasiões, evitei o puro ensaio literário ou leitura hermenêutica que, por um lado, não acho ser o propósito de uma biografia e, por outro, constitúam tecido morto na minha narrativa de vida. Não curei, portanto de escrever uma biografia crítica. 
Detive-me nas relações de O’Neill com o meio literário e com os movimentos / correntes da época, nomeadamente o neo-realismo e o surrealismo, dedicando o capítulo "Surrealismo, doença infantil do neo-realismo" a esmiuçar os 5 anos em que O’Neill se embrenhou na aventura surrealista. Este é o capítulo que posso classificar como o mais ensaístico, ou melhor, histórico-literário, da biografia. E corrijo ensaístico para históricoliterário porque tentei que ele fosse o mais factual possível, seguindo os passos de Alexandre O’Neill nos breves anos em que ajudou a fundar, se relacionou e, por fim, se desligou do Grupo Surrealista de Lisboa.

Outro aspecto a que dei especial importância foi a mitografia literária, na qual o próprio O’Neill tinha participado. Refiro-me aqui a textos declaradamente autobiográficos, como a crónica do J.L. em que conta a génese do poema "Um adeus português", relacionando-a com o caso amoroso que teve com Nora Mitrani, escritora francesa de origem búlgara pertencente ao grupo surrealista de André Breton, durante a estadia dela em Lisboa (O’NEILL, 2004, p.258-260). Refiro-me também à série de dados autobiográficos que o biografado ditou a Laurinda Bom, estudiosa de literatura e sua namorada à época, destinados a uma edição de poesia e publicados postumamente na revista Colóquio/Letras (O’NEILL, 1990). Este último é de um texto incompleto, lacunar e com inexatidões. Além de alguma informação factual que dele pude retirar, o texto interessou-me justamente pelas suas inexatidões, falhas e omissões: o que O’Neill não dizia ou truncava era também significante enquanto mitografia pessoal, representação de si como poeta destinada à posteridade, tentativa de reconstrução de um passado feita por alguém já doente, e desde sempre bastante renitente em se expor. Como bem notou, a propósito deste texto, Alexandre Pinheiro Torres, seu amigo de infância, "nenhum escritor pode ser mitófobo" (TORRES, 1992, p.32). Poder-se-á objetar que qualquer artista, e não só o escritor, é mitómano. Creio porém que, pela sua atividade, e pela condição da própria escrita, o escritor participa mais intensamente na elaboração de uma mitografia. É tarefa do biógrafo, portanto, desconstruir essa mitografia, seja a pessoal, seja a dos amigos do biografado - e note-se que digo descontrução, e não destruição, pois o mito é, também ele, material biográfico valioso. E o mito tanto pode presentificar-se em textos veladamente autobiográficos como em documentos muitas vezes considerados pelos biógrafos como os mais fiáveis, ou seja, as cartas. $\mathrm{Na}$ verdade, tudo, para um escritor, se pode tornar matéria literária, e é essa a dificuldade maior com que o seu biógrafo é obrigado a lidar, sob pena de 
cair na ingenuidade, ou na armadilha que qualquer escritor estende, voluntariamente ou não, a um seu imaginário biógrafo.

Tentei falar dos aspectos biográfico/literários sem perder o fio narrativo ou danificar a simulação de vida que pretendia. Este desejo entrava naturalmente em colisão com certa necessidade episodicamente experimentada: a de levar o meu percurso de biógrafa para o texto, enunciando as dificuldades e dúvidas com que deparava: desvelei os bastidores da biografia, falando deles de forma literal ou metafórica. Creio que é um caminho bem interessante no género biográfico, o da autorreflexão incorporada na narrativa de vida. Neste aspecto, julgo que o meu livro corresponde ao que Martine BoyerWeinmann designou como biografia de projeto ("biographie à project"), por oposição à "biografia branca", com narrador omnisciente, ausente, sem enunciação de princípios metodológicos, de legitimidade postulada (BOYER-WEINMANN, 2005, p.110-112). Pelo contrário, escolhi uma voz narrativa forte, intrusiva, opinativa, que se dirigia ao leitor: quis sublinhar que estava a escrever um livro, uma representação de uma vida, o que é diferente da vida em si. Obviamente, a vida vive-se, não se escreve - embora tal não implique que enquanto se escreve não se esteja também a viver.

Estas opções incomodaram alguns leitores, por certo habituados à biografia clássica, em que o autor se dilui na subjetividade do biografado, e a história decorre sem sobressaltos ou dúvidas. $\mathrm{Na}$ verdade, como já bem compreendiam os primeiros romancistas ingleses do século XVIII, ou o nosso Camilo posteriormente, o leitor comum quer é história, factos, e aborrece-se com divagações, que o apartam do fluxo de vida, preferindo que lhe não sejam mostrados os bastidores da biografia ${ }^{3}$. Et pour cause: as minhas breves interrupções deste teor serviram-me para lembrar ao leitor que estava a ler um livro.

Também o estilo foi questão para mim. Não falo aqui, repito, de escrever bem ou mal. Situando-se, como tudo se situava, na especificidade do literário, julguei necessária alguma adequação da forma ao escritor biografado. Dou um exemplo extremo e porventura controverso: ser-me-ia difícil aceitar uma biografia de Kafka escrita em estilo barroco. Tentei por isso adaptar a minha escrita ao estilo despojado e dégonflé de Alexandre O’Neill. Não se trata aqui, é claro, de imitação ou pastiche, e muito menos de identificação,

\footnotetext{
${ }^{3}$ Curiosamente, o próprio Alexandre O’Neill, no poema "Periclitam os Grilos", dá conta deste leitor "que me pede história / que já traz engatilhada, / leitor que não se habitua / a que não aconteça nada" (O’NEILL, 2000, p. 140).
} 
seja ela ao nível estilístico ou de personalidade. A identificação é, avisa Richard Holmes, palavra perigosa em biografia, conducente a um estado apaixonado ou amoroso, luz tão forte que encandeia e pode cegar o biógrafo (HOLMES, 1995, p.66-67). Biógrafo e biografado são, pois, duas personalidades distintas. O biógrafo é também uma pessoa historicamente determinada, que visita o passado e faz dele uma interpretação que é a sua, subjetivamente determinada também. Mas, sendo a biografia o encontro de duas identidades, é bom que falem uma língua aproximada. Para cada escritor será portanto necessária uma nova língua e, creio, uma nova forma ou estrutura narrativa. Um exemplo desta adaptação estrutural é o capítulo "Dicionário de Ideias Feitas de Braithwaite", da biografia de Flaubert escrita por Julian Barnes, O papagaio de Flaubert, construído a partir da citação do Diccionnaire des idées reçues escrito pelo biografado (BARNES, 1984, p. 181 -187).

Por outro lado, e pelo que venho enunciando, não fique a ideia de que escrevi uma biografia intelectual - denominação mais ou menos consensual para as histórias de vida de escritores centradas no seu trabalho de escrita, circunscritas à génese e produção de uma obra. São biografias parciais. E a mim, interessava-me a dinâmica do sujeito, a vida do corpo e a sua representação.

Por isso a minha pesquisa foi alargada, incluindo entrevistas a amigos e conhecidos não escritores, ou às mulheres e esposas. Pretendia alcançar o homem O’Neill - que tinha sido poeta. E tudo era uma e a mesma coisa - tanto mais num biografado que tinha escrito: "A poesia é a vida? Pois claro! Conforme a vida que se tem o verso vem - e se a vida é vidinha, já não há poesia que resista.”(O’NEILL, 2000, p.249)

Outro género de biografia parcial, que também não estava no meu horizonte, é aquela que omite ou secundariza a obra, toda interessada na parte mais suculenta e fácil da vida de um escritor - principalmente, e de forma muito óbvia, o sexo e as relações amorosas. Temos, aliás, um exemplo português do início do século $\mathrm{XX}$, intitulado Os amores de Camilo, escrito por um dos primeiros biógrafos de Camilo Castelo Branco, onde a obra é utilizada apenas como fonte autobiográfica. Ou ainda a biografia clínica de Paulo Osório, Camilo: a sua vida, o sen génio, a sua obra, que trata Camilo como um doente (grave) a diagnosticar. Os exemplos pululam e prolongam-se pelo século XX. São, de facto, biografias parciais. Porém hesito em chamar-lhes literárias pelo simples facto de o biografado ser escritor - pois como compreender que o próprio merecimento de se ser 
biografado, a obra, seja silenciado no ato de biografar? Poderia talvez chamar-lhes biografia de Judas, citando de forma enviesada a frase célebre de Oscar Wilde: "Every great man nowadays has his disciples, and it is always Judas who writes the biography."

Defendi atrás uma adequação da forma à vida que se conta, não só ao nível da escrita, mas também no que toca à estrutura da biografia. No caso de Alexandre O’Neill, era visível a importância que o testemunho oral tinha na operação biográfica. Não só ele tinha sido um morto precoce (morreu com 61 anos) como tinha ficado na memória de muitas pessoas vivas. Por outro lado, por motivos vários, eu não tinha acesso a papéis pessoais - apenas quatro ou cinco cartas, além da correspondência publicada por Mário Cesariny, seu amigo desde os tempos do Surrealismo.

Mas havia ainda outra causa pela qual se impunha o recurso à história oral, que me parecia ditado pelo próprio ser poético do biografado. Quase todos os seus poemas tinham originalmente dedicatória a amigos ou a mulheres. O’Neill tinha mesmo escrito duas séries de poemas a que chamou "Para um grupo de amigos" e "Amigos pensados". Numa entrevista confessara que não sacrificava um jantar com um amigo para acabar um soneto. Alexandre O’Neill não era o género de poeta solitário e introspectivo, arredado do mundo. De facto, era todo o contrário. De livrinho de apontamentos na mão, a fazer o que chamava as suas "recolhas", andava por Lisboa a escutar, na tasca, no café, no engraxador. Era um fascinado pelo espetáculo da vida.

A sua obra poética ressente esta pose vivencial: oralidade, reaproveitamento poético de cenas do quotidiano, frases e expressões alheias apanhadas na vertigem do dia-adia. Em 1979, numa entrevista ao jornal A Capital, explicou: "Na minha poesia desarticulo, desmonto a conversa comum e depois remonto-a de outra forma, o que a torna grotesca, satírica. Preocupo-me mais com a maneira de dizer do que com a maneira de ver ou de imaginar.” (O’NEILL, 1979, p.5)

À medida que ia conhecendo o meu biografado, percebia que não só os amigos deviam ter voz, como essa voz deveria passar incólume para a narrativa. Decidi, portanto, não diluir no meu discurso os testemunhos orais que recolhi - fiz, assim, o que chamei uma samplagem das vozes dos meus depoentes. Roubei o termo samplagem ao campo da música electrónica. O sampler é uma máquina que atua fundamentalmente como um 
repositório de sons, de vozes, ou de frases musicais já existentes, que são reutilizados no contexto de uma nova música. O sampler é portanto um instrumento de citação, de manipulação - e utilizo aqui manipular no sentido primário da palavra, 'imprimir forma' - e de montagem.

Coincidentemente, o conceito de montagem não era de todo estranho a Alexandre O’Neill. Roubava das ementas de restaurante, dos anúncios de jornal, de letreiros na rua ou no barbeiro, das conversas da tasca e do autocarro, de cartões de visita, da suas memórias juvenis. Depois montava, e pela montagem recontextualizava. Era uma prática comum nos seus textos, principalmente na prosa. Em 1969, escreveu no texto "Monstruário dois": "Ainda mais excitante que escrever - é estar à mesa de montagem..." Quando descobri no jornal esta prosa, inédita em livro, já ia avançada no meu trabalho. Como se pode calcular, a frase bailou cintilante durante muito tempo sob os meus olhos: era, para mim, a legitimação do processo que tinha empreendido.

Regresso finalmente à biografia literária e à sua central e controversa questão, a relação entre a obra e a vida, desta vez do ponto de vista do leitor, interrogando-me sobre a sua função, ou seja, sobre o tipo de relações que, ao nível da recepção de um autor, podem ser estabelecidas entre a sua biografia e a sua obra.

Dos numerosos relatos e reflexões de biógrafos, mas também da minha experiência, vim a concluir que a biografia tem variadas utilizações, devo dizer que nem todas recomendáveis. Assumindo o duplo papel de advogada de deus e do diabo, resumo os pontos da contenda. A biografia literária pode prolongar o gosto que se tem por um autor - mas também pode servir para aceder às suas fraquezas, induzindo o leitor na ideia de que, entrando na privacidade do escritor, toma de alguma maneira posse dele.Em alguns casos, a biografia de um escritor contextualiza a obra - mas pode também servir para o crítico preguiçoso ou o leitor desprevenido tirarem ilações abusivas e violentarem a obra pela leitura biografista.

Por último, mas não menos importante, a biografia literária pode conduzir à obra um novo leitor - mas também arrisca substituir-se-lhe. Tomo um exemplo. Sabemos bem que a escrita difícil de James Joyce é frequentemente trocada pela leitura da justamente célebre biografia escrita por Ellmann. Seriam talvez leitores que, na ausência de uma 
biografia, nunca acederiam à obra. E, neste ponto, pergunto-me se, de modo semelhante, o ensaio literário ou o artigo crítico conduz necessariamente à leitura da obra, ou se é destinado a tal - e se, tantas vezes, à semelhança da biografia, a não substitui.

Todas estas considerações, porém, continuam reféns do velho paradigma - o de que a biografia é um género secundário em relação à obra. No fundo, pede-se aos biógrafos que não sejam biografistas - e ao mesmo tempo que conduzam o leitor para a verdadeira razão da sua existência: a obra do biografado. Ora, a biografia é uma obra em si - literária ou não. É uma narrativa factual cujo objecto é um escritor, e tem uma legitimação própria, intrínseca. E talvez uma das tarefas do biógrafo seja, justamente, ajudar o leitor a separar aquilo que demasiado tempo andou promiscuamente ligado: a vida e a obra.

\section{BIBLIOGRAFIA}

BARNES, Julian, O Papagaio de Flaubert. Trad. Ana Maria Amador. Lisboa: Quetzal, 1988.

BOYER-WEINMANN, Martine, La relation biographique. Enjeux contemporains. Seyssel: Champ Vallon, 2005.

DOSSE, François, Le pari biographique. Paris: La Découverte, 2005.

FONSECA, Rubem, Diário de um Fescenino. Porto: Campo das Letras, 2003.

HAMILTON, Nigel. "Thomas Mann" in Jeffrey Meyers, ed., The Craft of Literary Biography. New York: Schocken Books, 1985.

HOLMES,Richard. Footsteps. Adventures of a Romantic Biographer. London: Flamingo, 1995.

O’NEILL, Alexandre, "A minha poesia tende para o epigrama", entrevista conduzida por António Carvalho, A Capital, Lisboa, p.5, 24/10/79.

"Elementos para Uma Biografia (1924-1953)", apresentados e anotados por Laurinda Bom, Colóquio/Letras no 113-114, Lisboa, janeiro-abril de 1990.

2000.

Poesias Completas, com inclusão de dispersos. Lisboa: Assírio \& Alvim,

Uma Coisa em forma de Assim. ed. de Maria Antónia Oliveira. Lisboa: Assírio \& Alvim, $3^{\text {a ed., }} 2004$.

PARK, Catherine N. Biography. Writing Lives. New York and London: Routledge, 2002. 
Revista $\because$...

Desassossegi:

TORRES, Alexandre Pinheiro. “Alexandre O’Neill, Eu e Uma Biografia Apressada”. JL, p.32, 6/10/1992.

WOOLF, Virginia. Collected Essays. vol. IV. London: Hogarth Press, 1966.

Artigo recebido em 28 de Março de 2012 e aprovado em 31 de Maio de 2012 